\title{
Ecofisiologia e rendimento forrageiro do capim elefante roxo em função de adubação nitrogenada
}

Aires Souza, J.T. '; de Farias Ramos, J.P. ${ }^{2}$; Fernandes Costa, R. ${ }^{2}$; Lima Araújo, D. ${ }^{3}$; Correia Guedes, P.L. ${ }^{2}$; Pontes Freitas, R. ${ }^{2}$; Silva Ribeiro, J.E. ${ }^{3}$ e Ribeiro Cavalcante, V. ${ }^{2}$

Instituto Nacional do Semiárido (INSA) Campina Grande. Paraíba. Brasil.

${ }^{2}$ Empresa Paraibana de Pesquisa. Extensão Rural e Regularização Fundiária - EMPAER. Paraíba. Brasil.

3Programa de Pós Graduação em Agronomia - Centro de Ciências Agrárias - Universidade Federal da Paraíba. Brasil.

PALAVRAS CHAVE ADICIONAIS

Produtividade.

Pennisetum purpureum.

Nitrogênio.
Trocas gasosas.

\section{RESUMO}

A maximização da produtividade vegetal é almejada em qualquer cultivo, inclusive de Pennisetum purpureum, entretanto, isto depende do estado nutricional das plantas, nesse aspecto $\circ$ nitrogênio exerce função essencial. O objetivo da pesquisa foi avaliar os aspectos ecofisiológicos e o rendimento forrageiro do capim elefante roxo em função de adubação nitrogenada. $O$ experimento foi realizado na Estação Experimental de Alagoinha, pertencente à Empresa Paraibana de Pesquisa, Extensão Rural e Regularização Fundiária (EMPAER), localizada no município de Alagoinha, estado da Paraíba, Brasil. Utilizou-se o delineamento de blocos ao acaso, com cinco tratamentos e quatro repetições. Os tratamentos consistiram na aplicação de 0, 20, 40, 60 e 80 $\mathrm{kg}$ de $\mathrm{N}$ ha- ${ }^{-}$. As variáveis avaliadas foram: índice de clorofila a, b e total, fotossíntese líquida, concentração interna de carbono, eficiência instantânea de carboxilação, eficiência do uso da chuva, pegada hídrica cultural, eficiência de uso do nitrogênio, produtividade de matéria verde e seca e capacidade de suporte para vacas leiteiras. $\mathrm{O}$ aumento das doses de $\mathrm{N}$ estimula positivamente os índices de clorofila, trocas gasosas, eficiência de uso da chuva, pegada hídrica cultural, produtividade e capacidade de suporte animal do capim elefante roxo, entretanto, reduz a eficiência de uso do $\mathrm{N}$.

\section{Ecophysiology and forage yield of purple elephantgrass as a function of nitrogen fertilization}

\section{SUMMARY}

\section{ADDITIONAL KEYWORDS}

Gas exchange.

Productivity.

Pennisetum purpureum.

Nitrogen.

\section{INFORMATION}

Cronología del artículo.

Recibido/Received: 27.05 .2018

Aceptado/Accepted: 30.06 .2019

On-line: 15.10 .2019

Correspondencia a los autores/Contact e-mail:

thyago.aires@insa.gov.br

\section{INTRODUÇÃO}

Atualmente no mundo há uma busca constante pela maior eficiência dos sistemas produtivos, inclusive pecuários, isto pode ocorrer, dentre outras formas, pelo melhoramento genético das raças para os fins desejados, ou pelo
The maximization of vegetable productivity indices is sought in any cultivation, including of Pennise tum purpureum, however, this depends on the nutritional status of the plants, in this aspect the nitrogen exerts essential function. The objective of the research was to evaluate the ecophysiological aspects and forage yield of purple elephantgrass as a function of nitrogen fertilization. The experiment was accomplished at the Experimental Station of Alagoinha, belonging to the Paraiba Research Company, Rural Extension and Land Regularization, located in the municipality of Alagoinha, state of Paraíba, Brazil; A randomized block design was used with five treatments and four repetitions. The treatments consisted of the application of $0,20,40,60$ and $80 \mathrm{~kg}$ of $\mathrm{N}$ ha-1. The variables evaluated were: chlorophyll $a, b$ and total index, liquid photosynthesis, internal carbon concentration, instantaneous carboxylation efficiency, rain use efficiency, cultural water footprint, nitrogen use efficiency, productivity of green and dry matter and carrying capacity for dairy cows. The increase of $\mathrm{N}$ doses positively stimulates the indexes of chlorophyll, gas exchange, rain use efficiency, cultural water footprint, productivity and animals carrying capacity of the purple elephant grass, however, reduces the efficiency of use of $\mathrm{N}$.

aumento da capacidade de suporte animal da propriedade rural através de manejos que potencializem a produtividade das plantas forrageiras (Silva et al. 2018, p. 258).

Na região Nordeste do Brasil a bovinocultura leiteira se destaca como uma das principais fontes de renda na 
maioria das propriedades rurais, esta atividade tem como base alimentar animal o cultivo de gramíneas perenes, como o capim elefante (Pennisetum purpureum Schum.) (Santos et al., 2013, p. 1034). Esta forrageira possui alta taxa de crescimento e produtividade, bom valor nutritivo e grande aceitação pelos animais, tanto picada no cocho como em pastejo direto (Santos et al., 2012, p. 503).

As condições edafoclimáticas do Agreste Paraibano, com precipitações acima de $1.000 \mathrm{~mm}$ anuais, favorecem a manutenção do crescimento, desenvolvimento e produtividade desta gramínea em altos níveis, fator determinante, principalmente para a redução de custos com suplementação hídrica via irrigação (Neves, 2017, p. 75). Apesar dos benefícios ambientais, os aspectos nutricionais e o rendimento das plantas forrageiras são afetados por diversos fatores, como: idade, altura de corte, características morfológicos e/ou anatômicas e adubação (Costa et al., 2016, p. 37). Dentre os nutrientes necessários para as plantas, o nitrogênio (N) é essencial quando se busca obter altas produtividades, pois, quando absorvido, aumenta o número de células em divisão e estimula o alongamento celular, potencializando, desse modo, as taxas de crescimento e o desenvolvimento das plantas, principalmente gramíneas (Martuscello et al., 2016, p. 569).

Essa dependência ocorre devido às funções vitais do $\mathrm{N}$ na planta, sendo constituinte de proteínas, enzimas, coenzimas, ácidos nucleicos, fitocromos e clorofila, além de afetar as taxas de iniciação e expansão foliar (Souza et al., 2011, p. 998). A deficiência deste macronutriente pode provocar má formação e baixa densidade de clorofila nas folhas, além de prejuízo às trocas gasosas, reduzindo a eficiência fotossintética das plantas, principalmente em gramíneas $\mathrm{C}_{4}$, como o capim elefante, onde o $\mathrm{N}$ pode representar até $5 \%$ da sua matéria seca (Barhoumi et al., 2010, p. 154)

Neste contexto, objetivou-se avaliar os aspectos ecofisiológicos e o rendimento forrageiro do capim elefante roxo em função de adubação nitrogenada.

\section{MATERIAL E MÉTODOS}

A pesquisa foi realizada de junho a agosto de 2017 na Estação Experimental de Alagoinha, pertencente à Empresa Estadual de Pesquisa Agropecuária da Pa- raíba S.A. - EMEPA-PB, localizada na mesorregião do agreste paraibano, no município de Alagoinha, estado da Paraíba, Brasil. A estação fica situada nas coordenadas geográficas $6^{\circ} 57^{\prime} 00^{\prime \prime} \mathrm{S}$ e $35^{\circ} 32^{\prime} 42^{\prime \prime} \mathrm{W}$, com altitude de $154 \mathrm{~m}$. O clima da região, segundo a classificação de Köppen, é do tipo As', quente e úmido (Alvares et al., 2013, p. 713), com a época chuvosa iniciando-se entre os meses de fevereiro e março, prolongando-se até julho ou agosto. A precipitação ocorrida durante o período experimental (300,3 $\mathrm{mm}$ ) se encontra na Tabela I, o solo da área foi classificado como LUVISSOLO CRÔMICO Pálico abrúptico (Embrapa, 2013, p. 167).

O experimento foi realizado em blocos ao acaso com cinco tratamentos e quatro repetições, totalizando 20 parcelas, que foram dimensionadas com área de 25 $\mathrm{m}^{2}$. O capim elefante foi cultivado em espaçamento de $1 \times 0,2 \mathrm{~m}^{-1}$ entre fileiras e plantas, respectivamente, correspondente à uma densidade de 50.000 plantas ha $^{-1}$ e 125 plantas por parcela. Utilizou-se a ureia (45\% de $\mathrm{N})$ como fonte de nitrogênio. Assim, os tratamentos foram $0,20,40,60$ e $80 \mathrm{~kg}$ de $\mathrm{N} / \mathrm{ha}^{-1}$, ou seja, 0 ; 44,5; $89 ; 133,5$ e $178 \mathrm{~kg}$ de ureia/ha-1 ${ }^{-1}$ calculadas com base na recomendação de Santos et al. (2008, p. 134). A adubação foi realizada de forma parcelada, sendo a primeira efetuada após o corte de uniformização na capineira e a segunda após 30 dias.

Antes do plantio, foram colhidas 15 amostras simples do solo na profundidade de $0-40 \mathrm{~cm}$ da área experimental, em seguida transformadas em uma amostra composta encaminhada para o laboratório de solos do Departamento de Engenharia Rural do Centro de Ciências Agrárias, Universidade Federal da Paraíba em Areia-PB para caracterização quanto à fertilidade, os resultados se encontram na Tabela II.

As variáveis avaliadas foram índice de clorofila $a$ $(\mathrm{Cl} \mathrm{a}), b(\mathrm{Cl} \mathrm{b})$ e total ( $\mathrm{Cl}$ total), fotossíntese líquida (A), concentração interna de carbono $(\mathrm{Ci})$, eficiência instantânea de carboxilação (ECi), eficiência do uso da chuva (EUC), pegada hídrica cultural (PHC), eficiência de uso do nitrogênio (EUN), produtividade de matéria verde (PMV), produtividade de matéria seca (PMS) e capacidade de suporte para vacas leiteiras (CS).

A determinação da clorofila $a$, $b$ e total foi realizada por um método não destrutivo em uma folha recém-expandida de dois perfilhos por parcela, sendo aferidas medições na parte mediana da folha no horário compreendido entre 08h30 e 09h30, utilizando-se um

Tabela I. Dinâmica da precipitação pluviométrica ocorrida durante o período experimental (Dynamics of rainfall precipitation occurred during the experimental period).

\begin{tabular}{lcccc}
\hline Período Experimental (Dias) & Dias sem chuva & Dias com chuva & Dias com chuva $>10 \mathrm{~mm}$ & $\%$ \\
\hline 62 & 28 & 34 & 7 & 20,6 \\
Dias com chuva entre 5-10 mm & $\%$ & Dias com chuva $<5 \mathrm{~mm}$ & $\%$ & Precipitação Total (mm) \\
8 & 23,5 & 19 & 55,9 & 300,3 \\
\hline
\end{tabular}

Tabela II. Atributos químicos do solo quanto à fertilidade na camada de $\mathbf{0}-\mathbf{4 0} \mathrm{cm}$ do solo (Soil chemical attributes regarding fertility in the layer of $0-40 \mathrm{~cm}$ of soil).

\begin{tabular}{lcccccccccccc}
\hline $\mathrm{pH}$ & $\mathrm{P}$ & $\mathrm{K}^{+}$ & $\mathrm{Na}^{+}$ & $\mathrm{H}^{+}+\mathrm{Al}^{+3}$ & $\mathrm{Al}^{+3}$ & $\mathrm{Ca}^{+2}$ & $\mathrm{Mg}$ & $\mathrm{V} \%$ & $\mathrm{CTC}$ & $\mathrm{M} . \mathrm{O}$ & \\
\hline $\mathrm{H}_{2} \mathrm{O}(1: 2,5)$ & $\mathrm{mg} / \mathrm{dm}^{3}$ & & -171 & 0,40 & 5,25 & 0,5 & 3,55 & 1,70 & 55,12 & 11,03 & 18,68 &
\end{tabular}

P, K, Na: Extrator Mehlich 1; H + Al: Extrator Acetato de Cálcio 0,5 M, pH 7,0; H + Al: Extrator Acetato de Cálcio 0,5 M, pH 7,0; Al, Ca, Mg: Extrator $\mathrm{KCl} 1 \mathrm{M}$; M.O.: Matéria Orgânica - Walkley-Black; V\%:saturação de base. 
clorofilômetro eletrônico (ClorofiLog Falker CFL 1030, Brasil).

Nas mesmas folhas e no mesmo horário, foram avaliadas a fotossíntese líquida (A) $\left(\mu \mathrm{mol} \mathrm{m} \mathrm{m}^{-2} \mathrm{~s}^{-1}\right)$ e a concentração interna de carbono (Ci) $\left(\mu \mathrm{mol} \mathrm{m} \mathrm{m}^{-2} \mathrm{~s}^{-1}\right)$, utilizando-se um analisador de gás carbônico a infravermelho portátil (IRGA) (ACD, model LCPro SD, Hoddesdon, UK), com temperatura ajustada a $25^{\circ} \mathrm{C}$, irradiação de $1.400 \mu \mathrm{mol}$ fótons $\mathrm{m}^{-2} \mathrm{~s}^{-1} \mathrm{e}$ fluxo de ar de $200 \mathrm{~mL} \mathrm{~min}^{-1}$. De posse dos dados supracitados, foi calculada a eficiência instantânea de carboxilação ECi $\left[\left(\mu \mathrm{mol} \mathrm{m}{ }^{-2} \mathrm{~s}^{-1}\right) /\left(\mu \mathrm{mol} \mathrm{m}{ }^{-2} \mathrm{~s}^{-1}\right)\right]$ relacionando a fotossíntese líquida (A) com a concentração interna de carbono (Ci).

A produtividade de matéria verde (PMV) em Mg/ ha $^{-1}$ foi determinada através da colheita das plantas aos 60 dias após o corte de uniformização, considerando-se o peso médio da parcela e em seguida multiplicados pela população de plantas por hectare. Após este processo, retirou-se uma sub amostra de cada tratamento para pré-secagem em estufa a $65^{\circ} \mathrm{C}$ por 72 horas, a fim de quantificar o teor de matéria seca (MS) de acordo com metodologia preconizada pela AOAC (1990), em seguida a produtividade de matéria seca (PMS) também em $\mathrm{Mg} / \mathrm{ha}^{-1}$ foi obtida pelo produto da multiplicação da PMV e os teores de MS. A partir destes valores calculou-se a EUC dada em $\mathrm{kg} \mathrm{MS} \mathrm{ha}^{-1}$ $\mathrm{mm}^{-1}$, estimada pela divisão da PMS em $\mathrm{kg} / \mathrm{ha}^{-1}$ pela quantidade de chuva acumulada durante o período experimental (Tabela I). A pegada hídrica cultural $\mathrm{m}^{3}$ $\mathrm{H}_{2} \mathrm{O}$ Mg MS ha ${ }^{-1}$ foi calculada dividindo-se a precipitação observada durante o ciclo de cultivo pela PMS da cultura (Carvalho \& Menezes, 2014, p. 143), enquanto que a eficiência de utilização do nitrogênio (EUN) foi determinada relacionando-se o rendimento de MS com a dose de $\mathrm{N}$ aplicada.

Foi realizada uma simulação da capacidade de suporte $(\mathrm{CP})$ do capim elefante (CE) em um hectare para vacas em lactação por um período de 180 dias. Conhecendo a produção de matéria seca (PMS) por ha $^{-1}$ e levando-se em consideração que uma vaca com peso médio vivo de $400 \mathrm{~kg}$ de (PV) consumindo $3 \%$ do PV x $60 \%$ CE na dieta com base na matéria seca, 20\% de volumoso, $19 \%$ de concentrado e $1 \%$ de minerais. Utilizou-se a formula: $\mathrm{CP}=(\mathrm{PMS} / \mathrm{ha}) /$ consumo individual x 180 dias, onde a $\mathrm{CP}=$ quantidade de animais.

Os resultados foram submetidos à análise de variância pelo teste $\mathrm{F}$, em seguida, os dados que apresentaram efeito significativo relativo às doses de nitrogênio foram submetidos à análise de regressão polinomial, utilizando para o processamento dos dados o software estatístico Statistical Analysis System (SAS/ STAT 9.3 (2011).

\section{RESULTADOS E DISCUSSÃO}

As doses de nitrogênio aplicadas ao solo propiciaram comportamento quadrático ao índice de clorofila $a$, onde a máxima eficiência física $(43,76)$ foi obtida quando adubou-se com $80 \mathrm{~kg}$ de $\mathrm{N} \mathrm{ha}^{-1}$ ou $178 \mathrm{~kg}$ de ureia $\mathrm{ha}^{-1}$, incremento de $32,6 \%$ em relação à mínima eficiência física $(33,0)$ obtida na dose de $11,71 \mathrm{~kg}$ de $\mathrm{N}$ ha $^{-1}$ ou $26 \mathrm{~kg}$ de ureia ha ${ }^{-1}$ e de $36 \%$ sobre as plantas que não receberam fertilização com nitrogênio (Figura 1A). Souto et al. (2015, p.1038) obtiveram elevação dos teores de pigmentos fotossintéticos em função do aumento das doses de cloreto de potássio na cultura de noni (Morinda citrifolia L.), correlacionando isto com a elevação dos teores de nitrogênio foliar, haja visto que sendo esse elemento é um dos principais precursores da molécula de clorofila (Mógor et al., 2013, p.366). Diversos autores verificaram relação direta entre a adubação nitrogenada e os incrementos dos índices de clorofila, como Souza et al. (2011, p. 998) em plantas cí-
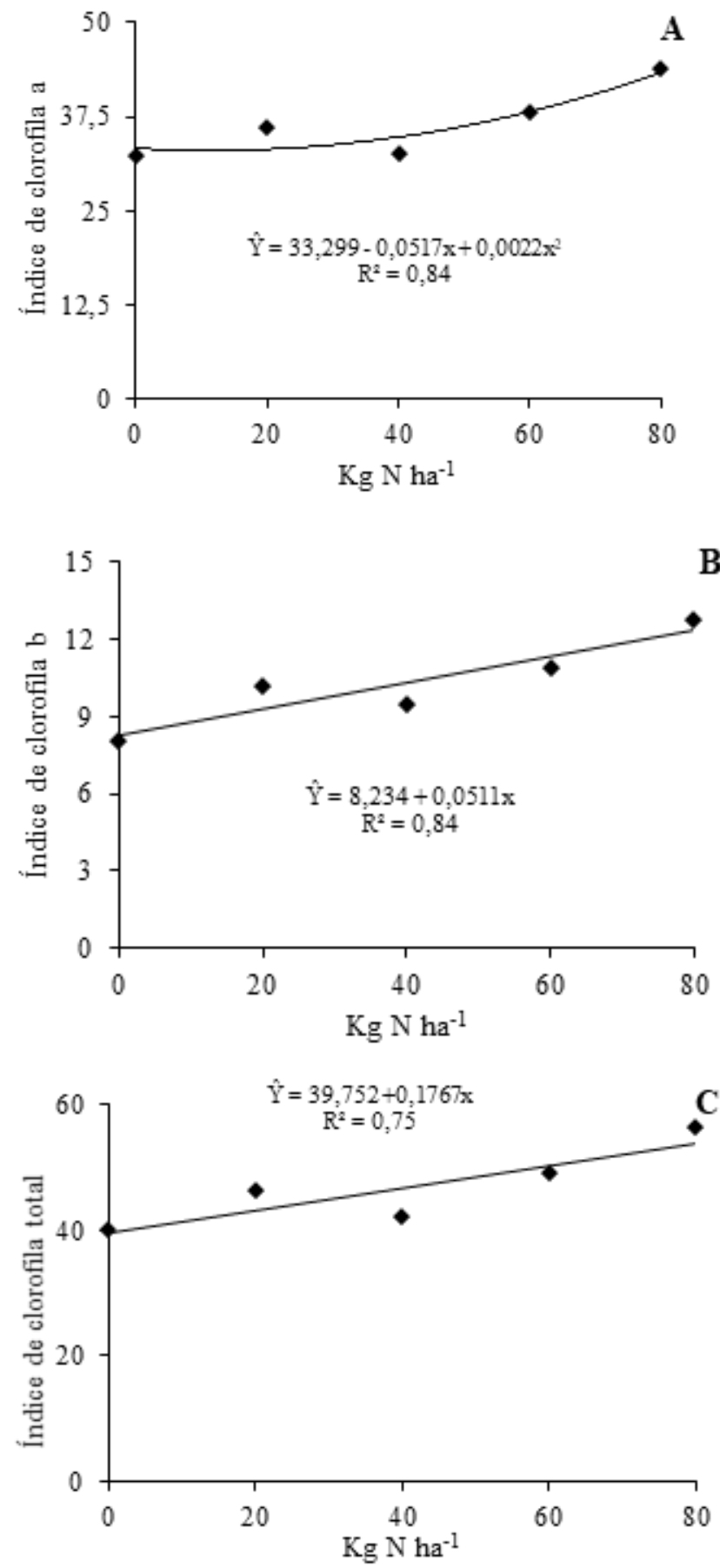

Figura 1. Índices de clorofila a (A), b (B) e total (C) de capim elefante em função de adubação nitrogenada (Indices of chlorophyll a (A), b (B) and total (C) of elephant grass as a function of nitrogen fertilization). 
tricas, Godoy et al. (2007 p.41) em milho (Zea mays L.) e Costa et al. (2008 p. 1604) em capim marandu (Urochloa brizantha, cv. Marandu).

Os índices de clorofila $b$ e total responderam linearmente às doses de adubação nitrogenada, obtendo valores máximos $(12,78$ e 56,54$)$ ao se adubar com 80 $\mathrm{kg}$ de $\mathrm{N} \mathrm{ha}^{-1}$, incremento respectivo a 59 e 40,5\% em comparação às plantas cultivadas sem adubação nitrogenada (Figuras 1B e C). Ferreira (2017, p.78) obteve resposta quadrática para o índice de clorofila conforme aumentou-se as doses de nitrogênio aplicadas ao solo, relacionando este resultado ao papel essencial do $\mathrm{N}$ no metabolismo das plantas, principalmente gramíneas, participando diretamente da biossíntese de proteínas e clorofilas.

Souto et al. (2015 p.1038) ressaltam que o aumento nos teores de clorofila b é uma característica importante, pois esta capta energia de outros comprimentos de onda e transfere para a clorofila $a$, que efetivamente atua nas reações fotoquímicas da fotossíntese. $\mathrm{O}$ aumento dos teores de clorofila pode estar relacionado a um bom estado nutricional das plantas, uma vez que a clorofila é uma forma indireta para avaliar a nutrição das plantas (Morgado et al., 2011, p. 74,; Taiz \& Zeiger, 2017, p. 186)

O aumento das doses de $\mathrm{N}$ exerceu comportamento quadrático sobre a taxa de fotossíntese líquida (Figura 2A), as plantas obtiveram máxima atividade fotossintética $\left(24,07 \mu \mathrm{mol} \mathrm{m} \mathrm{m}^{-2} \mathrm{~s}^{-1}\right)$ quando adubadas com a dose de $38,59 \mathrm{~kg}$ de $\mathrm{N} \mathrm{ha}^{-1}$, incremento de 18,7\% em relação às plantas cultivadas sem adubação nitrogenada $(20,27$

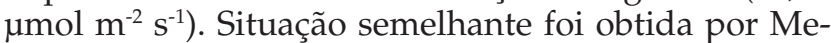
neses $(2015$, p.49) ao adubar capim elefante verde com a dose máxima de 79,8 Mg de composto orgânico ha-1, obtendo taxa fotossintética de $26,9 \mu \mathrm{mol} \mathrm{m} \mathrm{m}^{-2} \mathrm{~s}^{-1}$.

O incremento das doses de ureia causou depleção na concentração interna de carbono $(\mathrm{Ci})$ das plantas de capim elefante roxo (Figura 2B) até 63,33 $\mathrm{mmol} \mathrm{mol}^{-1}$ com a adição de $31,52 \mathrm{~kg}$ de $\mathrm{N} \mathrm{ha}^{-1}$, entretanto, a partir deste ponto a $\mathrm{Ci}$ das plantas elevaram-se, alcançando

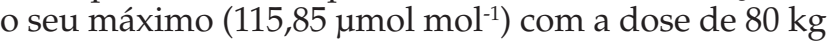
de $\mathrm{N} \mathrm{ha}^{-1}$, incremento de $83 \%$. A eficiência instantânea de carboxilação elevou-se quadraticamente até 0,4 mols de $\mathrm{CO}_{2} \mathrm{~m}^{-2} \mathrm{~s}^{-1} / \mathrm{mol}$ de $\mathrm{CO}_{2} \mathrm{~mol}^{-1}$ na dose máxima estimada de $37,5 \mathrm{~kg}$ de $\mathrm{N} \mathrm{ha}^{-1}$, superioridade de $39,4 \% \mathrm{em}$ comparação com a testemunha (Figura 2C).

Freire et al. (2014, p.88) ressaltam que o aumento da $\mathrm{Ci}$, como verificado ao se adicionar $80 \mathrm{~kg}^{\mathrm{de}} \mathrm{N} \mathrm{ha}^{-1} \mathrm{no}$ solo cultivado com capim elefante, indica que o $\mathrm{CO}_{2}$ não está sendo utilizado para a síntese de açúcares durante o processo fotossintético, o que propicia acúmulo desse gás, os autores apontam que pode haver a interferência de um fator não estomático nesse processo, podendo resultar em danos ao aparelho fotossintético das plantas.

A expressiva redução da eficiência instantânea de carboxilação observado nas folhas de capim elefante roxo a partir da aplicação de $37,5 \mathrm{~kg}$ de $\mathrm{N} \mathrm{ha}^{-1}$, possivelmente é um reflexo das altas taxas fotossintéticas (Figura 2A), em relação à depleção ocorrida na concentração interna de carbono das plantas (Figura 2B), pois, se o
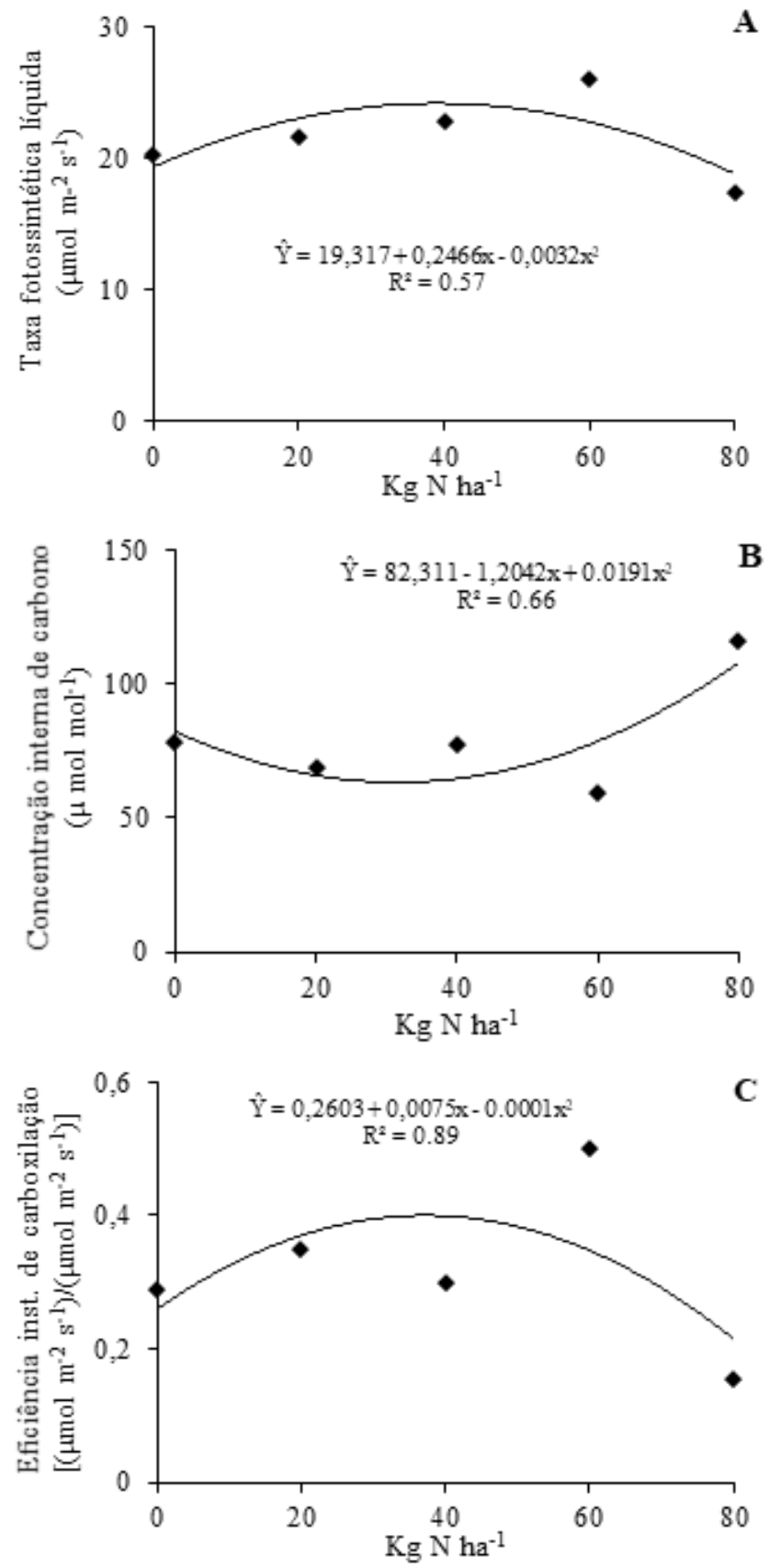

Figura 2. Taxa fotossintética líquida (A), concentração interna de carbono (B) e eficiência instantânea de carboxilação $(C)$ de capim elefante em função de adubação nitrogenada (Liquid photosynthetic rate $(A)$, internal carbon concentration (B) and instantaneous efficiency of carboxylation (C) of elephantgrass as a function of nitrogen fertilization).

$\mathrm{CO}_{2}$ interno diminui há um incremento no consumo de $\mathrm{CO}_{2}$ nos cloroplastos, devido ao aumento da atividade fotossintética, com isso a relação A/Ci também será elevada (LIMA et al., 2017, p.1500).

O aumento das doses de nitrogênio ao solo elevou de forma linear a eficiência de uso da chuva (EUC) pelas plantas ao nível de 0,2601 $\mathrm{kg}$ MS ha $\mathrm{mm}^{-1}$ por aumento unitário da dose de ureia (Figura 3A). Ao relacionar o valor máximo $\left(39,16 \mathrm{~kg}^{\mathrm{MS}}\right.$ ha $\left.\mathrm{mm}^{-1}\right)$ quan-

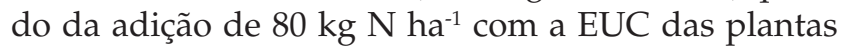
cultivadas no solo ausente de adubação (18,09 kg MS 

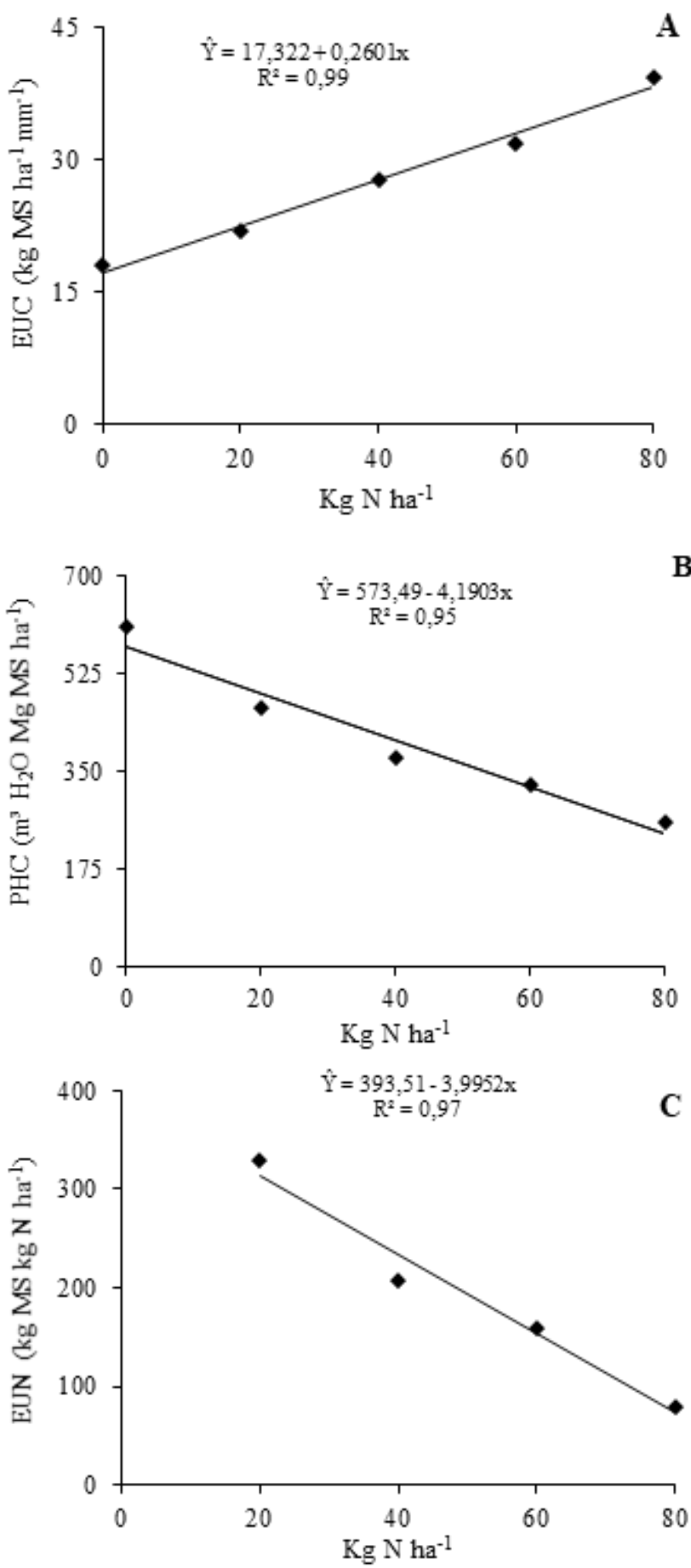

Figura 3. Eficiência de uso da chuva (A), pegada hídrica cultural (B) e eficiência do uso do nitrogênio (C) por capim elefante em função de adubação nitrogenada (Efficiency of rainfall use $(A)$, cultural water footprint (B) and efficiency of the use of nitrogen (C) by elephantgrass as a function of nitrogen fertilization).

ha $\mathrm{mm}^{-1}$ ), constata-se que o uso da ureia como fonte de $\mathrm{N}$ elevou a EUC em 116,5\%.

Rocha et al. (2017, p.40) cultivando milheto (Pennisetum glaucum) sob doses crescentes de nitrogênio obtiveram tendência semelhante a observada neste trabalho, assim como estes autores, é importante destacar que nestas condições de precipitação $(300,3 \mathrm{~mm})$, a capacidade produtiva das plantas de capim elefante roxo ainda não foi totalmente atingida, estando diretamente ligada à demanda de nitrogênio vegetal. Estes resultados possivelmente são consequência do aumento da absorção e assimilação de nitrato pelas plantas, haja vista que este acúmulo está diretamente ligado ao aumento do fornecimento do nutriente via adubação (Marschner, 2012, p. 140). Taiz \& Zeiger (2017, p. 354) ressaltam que o $\mathrm{N}$ é o elemento mineral mais exigido pela maioria das culturas, principalmente pelas de metabolismo $\mathrm{C}_{4}$, como o capim elefante, sendo este constituinte de muitos componentes da célula vegetal, incluindo aminoácidos, proteínas e ácidos nucleicos.

A pegada hídrica cultural contabiliza a quantidade de água consumida na produção de bens e serviços, estudos têm utilizado esta variável para designar o consumo de água por unidade de biomassa produzida em sistemas de produção vegetal (Carvalho \& Menezes, 2014, p.143). Neste trabalho observou-se comportamento linear decrescente, onde a maior pegada hídrica ocorreu para as plantas cultivadas na ausência de adubação nitrogenada, 608,4 $\mathrm{m}^{3} \mathrm{H}_{2} \mathrm{O} \mathrm{Mg} \mathrm{MS} \mathrm{ha-1}$ (Figura 3B). Isto significa que o não uso de ureia na adubação de capim elefante roxo exigiu mais água por $\mathrm{Mg}$ de matéria seca produzida. Entretanto, a adição de $80 \mathrm{~kg}$ de $\mathrm{N} \mathrm{ha}^{-1}$ reduziu esta pegada para $259,2 \mathrm{~m}^{3} \mathrm{H}_{2} \mathrm{O}$ Mg MS ha ${ }^{-1}$, depleção de 57,4\% na exigência hídrica da cultura.

Na Figura 3C observa-se que a eficiência de uso do nitrogênio foi inversamente proporcional às doses de $\mathrm{N}$ aplicadas, o aumento do fornecimento deste macronutriente de 0 para $80 \mathrm{~kg} \mathrm{ha}^{-1}$ propiciou uma depleção de $316,5 \%$ na EUN. Mochel Filho et al. (2016, p. 75) ressaltam que a eficiência de utilização do nitrogênio é um importante fator de avaliação da eficiência e sustentabilidade da adubação nitrogenada, pois estima a dose que apresentou melhor resposta.

De acordo com Martha Júnior et al. (2007, p. 130) e Costa et al. (2016 p. 34) adubações maiores, a partir de 50 a $60 \mathrm{~kg} \mathrm{~N} / \mathrm{ha} /$ ciclo de crescimento podem reduzir a eficiência do uso de $\mathrm{N}$ com aumento da dose fornecida, isto ocorre devido a perdas de nitrogênio por lixiviação e volatilização, que se tornam cada vez maiores com o aumento da dose de adubo nitrogenado.

$\mathrm{O}$ aumento no fornecimento de $\mathrm{N}$ elevou linearmente o rendimento forrageiro do capim elefante roxo em matéria verde e seca (PMV e PMS) até 70,2 e 11,76 $\mathrm{Mg} \mathrm{ha}^{-1}$, incremento de 85,4 e 99,3\% em comparação à produtividade das plantas não tratadas com suplementação nitrogenada, 37,87 e 11,76 $\mathrm{Mg} \mathrm{ha}^{-1}$ de MV e MS, respectivamente, (Figura 4A e B). Martuscello et al. (2016, p.380) ressaltam que o aumento na PMV e PMS com o incremento na adubação nitrogenada é explicado pela ação do nitrogênio como fator controlador dos diferentes processos de crescimento e desenvolvimento vegetal, proporcionando aumento de produção através da maior fixação de carbono pelas plantas. Os resultados obtidos demonstram a alta demanda do capim elefante roxo por $\mathrm{N}$, agindo este, como um estimulante e fonte de vigor, interferindo ativamente no rendimento forrageiro da cultura.

Na Figura 4C, observa-se que houve crescimento linear $(\mathrm{P}<0,05)$ para a capacidade de suporte do capim 

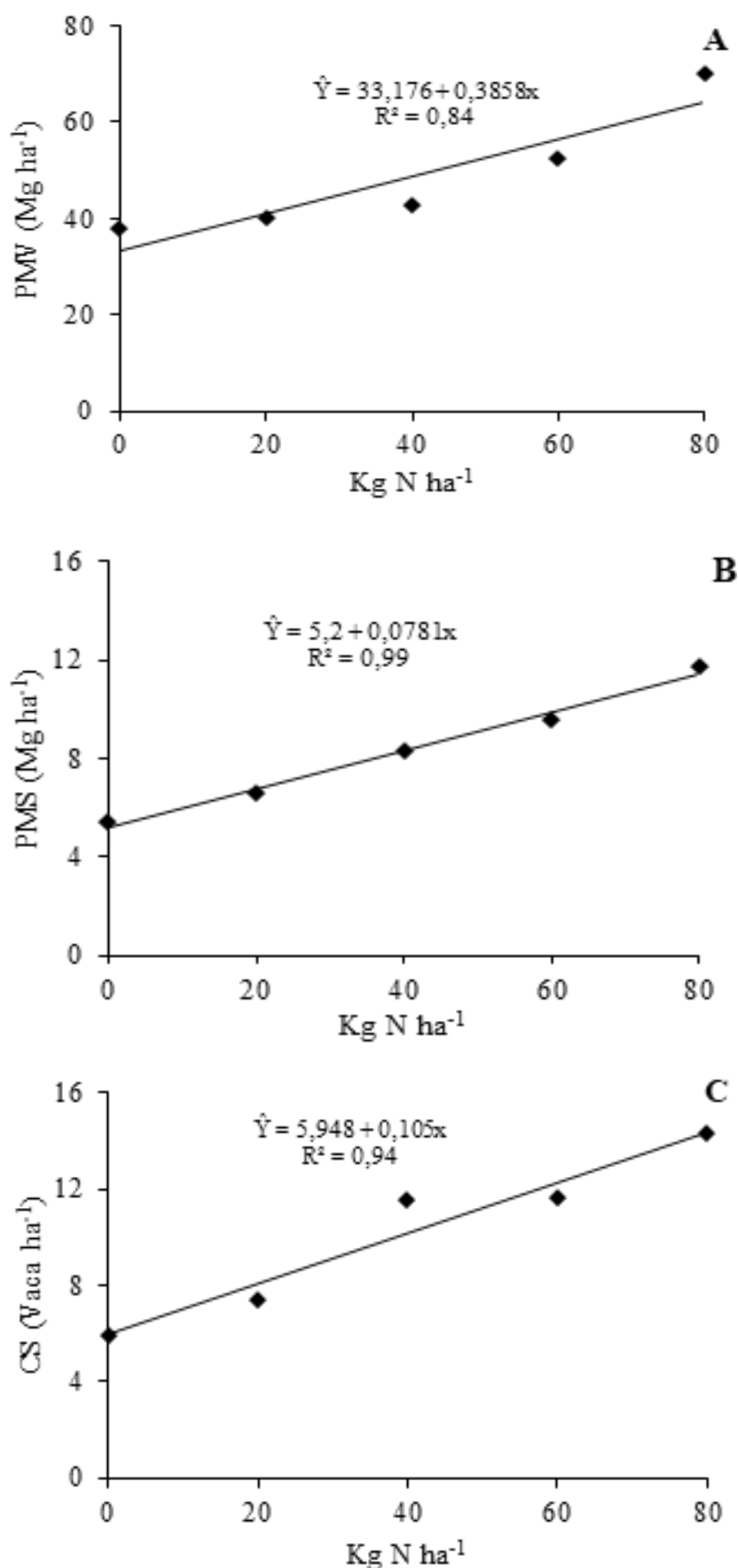

Figura 4. Produtividade de matéria verde (A), produtividade de matéria seca (B) e capacidade de suporte para vacas em lactação $(C)$ de capim elefante em função de adubação nitrogenada (Green matter yield $(A)$, dry matter yield (B) and support capacity for lactating cows (C) of elephantgrass as a function of nitrogen fertilization).

elefante em função da adubação nitrogenada para vacas zebuínas em lactação, quando adubou-se com 80 $\mathrm{kg} \mathrm{N} \mathrm{ha-1} \mathrm{o}$ aumento na capacidade de suporte chegou a $142 \%$ quando comparado ao tratamento controle $(0$ $\mathrm{kg} \mathrm{N} \mathrm{ha-1).}$

Em consequência ao estimulo no rendimento do capim elefante, o maior benefício da intensificação da adubação nitrogenada é o incremento no ganho animal por área, haja vista que a produtividade animal é função do seu potencial genético de produção e do meio ambiente onde ele está inserido, sendo a alimen- tação o mais importante fator do meio. $\mathrm{O}$ primeiro passo a ser dado quando se objetiva o aumento da produtividade animal de forma prática e econômica é produzir alimentos em quantidades e qualidade para os animais.

\section{CONCLUSÃO}

O aumento das doses de adubação nitrogenada estimula os índices de clorofila, trocas gasosas, eficiência de uso da chuva, pegada hídrica cultural e produtividade do capim elefante roxo, elevando consequentemente a capacidade de suporte para bovinos leiteiros;

Entretanto, a eficiência de uso do nitrogênio reduzse conforme há acréscimo nas doses de $\mathrm{N}$ adicionadas ao solo.

\section{BIBLIOGRÁFIA}

Alvares, C, Stape, J, Sentelhas, P, Gonçalves, J \& Sparovek, G 2013, 'Köppen's climate classification map for Brazil.', Meteorologische Zeitschrift, v. 22, n. 6, p. 711-728.

Association of official Analytical Chemists, 1990, AOAC. 'Official methods of analysis of the Association of Analytical Chemists'. 15.ed. Arlington: $1117 \mathrm{p}$.

Barhoumi, Z, Atia, A, Rabhi, M, Dieball, W, Abdelly, C \& Smaovi, A 2010, Nitrogen and $\mathrm{NaCl}$ salinity effects on the growth and nutrient acquisition of the grasses Aeluropus littoralis, Catapodium rigidum, and Brachypodium distachyum', Journal of Plant Nutrition and Soil Science, v. 173, n. 1, p. 149- 157.

Carvalho, A \& Menezes, R 2014, 'Pegadas hídricas em sistemas agropecuários na região semiárida do Nordeste do Brasil' , Revista Agro@ mbiente On-line, v. 8, n. 1, p. 142-148.

Costa, K, Faquim, V, Oliveira, I \& Rodrigues, R 2008, 'Doses e fontes de nitrogênio em pastagem de capim-marandu. II - nutrição nitrogenada da planta', Revista Brasileira de Ciência do Solo, v.32, p.1601-1607.

Costa, N, Paulino, V, Magalhães, J, Rodigues, B \& Santos, F 2016, 'Eficiência do nitrogênio, produção de forragem e morfogênese do capim-massai sob adubação', Revista Nucleus, v. 13, n.2, p. 31-40.

Empresa Brasileira de Pesquisa Agropecuária-EMBRAPA, 2013, Centro Nacional de Pesquisa de Solos. 'Sistema Brasileiro de Classificação de Solos', $2^{a}$ ed. Rio de Janeiro: Embrapa Solos.

Ferreira, A 2017, 'Doses de nitrogênio no milho safrinha sob efeito residual da co-inoculação na cultura da soja', Dssertação de Mestrado, visto em 20 de Maio, http://portal.unemat.br/media/files/AUREANE\%20 CRISTINA\%20TEIXEIRA\%20FERREIRA.pdf

Freire, J, Dias, T, Cavalcante, L, Fernandes, P \& Lima Neto, A 2014, 'Rendimento quântico e trocas gasosas em maracujazeiro amarelo sob salinidade hídrica, biofertilização e cobertura morta', Revista Ciência Agronômica, v. 45, n. 1, p. 82-91.

Godoy, L, Fernandes, D, Souto, L \& Villas Boas, R 2007, 'Uso do clorofilômetro no manejo da adubação nitrogenada para milho em sucessão a pastagem de Brachiaria decumbens', Ciência Rural, v.37, n.1, p.38-44.

Lima, G, Dias, A, Gheyi, H, Soares, L, Nobre, R, Pinheiro, F \& Silva, A 2017, 'Gas exchanges and production of colored cotton under salt stress and nitrogen fertilization', Biosciense Journal, v. 33, n. 6, p. 1495-1505.

Marschner, P 2012, 'Mineral Nutrition of Higher Plants'. 3. ed. London: Elsevier.

Martha Júnior, G, Vilela, L \& Sousa, D 2007, 'Adubação nitrogenada', In: Martha Júnior, G, Vilela, L, Sousa, D, 'Cerrado: Uso eficiente de corretivos e fertilizantes em pastagens', Planaltina-DF', Ed. Embrapa Cerrados, p. 117-144.

Martuscello, J, Majerowicz, N, Cunha, D, Amorim, P \& Braz, T 2016 'Características produtivas e fisiológicas de capim-elefante submetido 
à adubação nitrogenada', Archivos de Zootecnia, v. 65, n. 252, p. 565-570.

Meneses, A 2015, 'Morfologia de capim elefante adubado com compost orgânico proveniente da produção e do abate de pequenos ruminantes', Dissertação de Mestrado, visto em 09 de Maio, https:// ainfo.cnptia.embrapa.br/digital/bitstream/item/138331/1/cnpc-2015-Morfofisiologia.pdf

Mochel filho, W, Carneiro, M, Andrade, A, Pereira, E, Andrade, A, Cândido, M, Magalhães, J, Rodrigues, B, Santos, F \& Costa, N 2016, 'Produtividade e composição bromatológica de Panicum maximum cv. Mombaça sob irrigação e adubação azotada', Revista de Ciências Agrárias, v.39, n. 1, 81-88.

Mógor, Á, Barbizan, T, Pauletti, V, Oliveira, J \& Bettoni, M2013, 'Teores de clorofila em cultivares de tomateiro submetidas a aplicações foliares de magnésio', Pesquisa Agropecuária Tropical, v. 43, n. 4, p. 363-369.

Morgado, M, Fialho. J, Bruckner, C, \& Melo, L 2011, 'Nondestructive estimation of chlorophyll contente in yellow passion fruit leaves', Revista Brasileira de Agropecuária Sustentável, v. 1, n. 1, p. 74-78.

Neves, T 2017, 'Aproveitamento energético do biossólido gerado por indústria têxtil como fertilizante para produção de capim-elefante Cenchrus purpureus (Schumach.) Morrone', Dissertação de Mestrado, visto em 20 de Abril, http://www.cear.ufpb.br/arquivos/ppger/ documentos

Rocha, J, Santos, A, Silveira Júnior, O, Silva, R, Santos, J \& Oliveira, L 2017, 'Características agronômicas do milheto sob efeito ne nitrogênio nos sistemas consorciado e monocultivo' Revista Tecnologia e Ciência Agropecuária, v. 11, n. 1, p. 37-43.

Santos, D, Lira, M, Dubeux Júnior, J, Santos, M \& Mello, A 2008, 'Recomendação de adubação para a palma forrageira', In: FCavalcanti (ed.), Recomendações de adubação para o estado de Pernambuco: $2^{a}$ Aproximação, Instituto Agronômico de Pernambuco, Recife, PE. Santos, R, Azevedo, V, Freire, F, Rocha, A, Tavares, J \& Freire, M 2012, 'Extração e eficiência de uso de nutrientes em capim-elefante na presença de gesso', Revista Brasileira de Ciência do Solo, v.36, p.497-505. Santos, R, Freire, F, Azevedo, V, Rocha, A \& Tavares, J 2013, 'Produção de capim elefante e movimentação de cátions em função de gesso mineral', Revista Brasileira de Engenharia Agrícola e Ambiental, v. 17, n. 10, p.1030-1037.

SAS Institute Inc. SAS/STAT 9.3 ${ }^{\circledR}, 2011$, User's Guide. Cary, NC: SAS Institute Inc., Cary NC, USA. 8621 p.

Silva, M, Silva, A, Nascif, C \& Gameiro, A 2018, 'Interações entre indicadores zootécnicos e econômicos na análise e gestão da eficiência de fazendas leiteiras' Revista Empreendedorismo, Gestão e Negócios, v. 7, n. 7, p. 245-262.

Souto, A, Cavalcante, L, Gheyi, H, Nunes, J, Oliveira, F, Oresca, D 2015, 'Photosynthetic pigments and biomass in noni irrigated with saline waters with and without leaching', Revista Brasileira de Engenharia Agrícola e Ambiental. v. 19, n. 11, p.1035-1041.

Souza, T, Salomão, L, Andrade, T, Bôas, R, Quaggio, J 2011, 'Medida indireta da clorofila e sua relação com o manejo da adubação nitrogenada em plantas cítricas fertirrigadas', Revista Brasileira de Fruticultura, v. 33, n. 3, p. 993-1003.

Taiz, L \& Zeiger, E 2017, 'Fisiologia e Desenvolvimento Vegetal', 5. ed. Porto Alegre: Artmed, 819p. 